\title{
Comportment of heavy goods vehicle drivers in HIV spread along settlements around Kaduna: Kano road transport corridor in Nigeria
}

Idris $\mathrm{SH}$, Sambo $\mathrm{MN}$,
Obi $\mathrm{P}^{1}$

Department of Community Medicine, Ahmadu Bello University, ${ }^{1}$ Nigerian Institute of Transport Technology Zaria,

Nigeria

Address for the Correspondence:

Dr. Obi P

Head Medical Unit, Nigerian Institute of Transport Technology

Zaria, Nigeria.

E-mail: patrickobinitt@yahoo.com

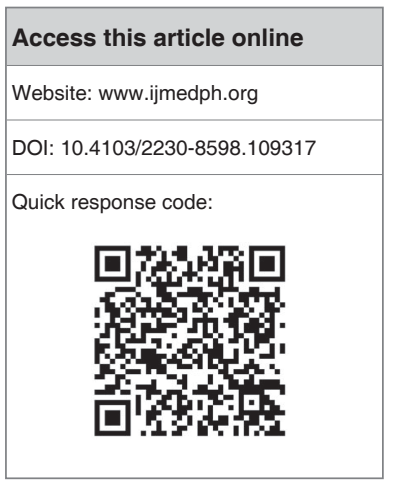

Background: Road transport remains the cheapest way to move goods and services across limitless boundaries in Nigeria. The collapse of the rail and water transport system, and the high cost of air transport have given rise to increasing road transport usage. This increases vulnerability to HIV/AIDS among Heavy Goods Vehicle (HGV) drivers due to long absence from home and constant interaction with the commercial sex workers (CSWs). Objectives: The study was performed to determine the sexual behaviour of HGV drivers while on transit within the inter-state transport corridor of Kaduna State in northern Nigeria. Materials and Methods: A descriptive cross-sectional study was conducted in Marraba-Jos along the Kaduna-Kano transport corridor. A structured questionnaire was used to study age, educational status, knowledge and attitude toward HIV/AIDS, and the sexual behavior of HGV drivers. Results: Three hundred and fifty HGV drivers participated in the study, of whom 273 drivers (78.0\%) had excellent knowledge on HIV/AIDS preventive measures and 218 drivers $(62.0 \%)$ had good attitude toward prevention. Frequency of having sex while on transit varied with 84 respondents (24\%) having sex at any available opportunity and $49(14 \%)$ having sex on a daily basis. Three hundred and twenty-two drivers $(92.0 \%)$ agreed in taking some preventive measure, of which $36.8 \%$ made use of condoms. One hundred and sixty-one drivers in the study $(46.0 \%)$ considered themselves a high-risk group to getting infected and $140(40.0 \%)$ agreed that public discussion on HIV/AIDS will help create the necessary awareness. Conclusion: The knowledge of HIV/AIDS among HGV drivers was found to be high, attitude toward prevention was good, and there was fair appreciation of public health intervention toward combating HIV/AIDS when compared to previous studies done on road transport workers in the country.

Key words: Heavy goods vehicle drivers, HIV/AIDS, sexual behavior

\section{INTRODUCTION}

From 1981, when cases of Pneumocystic carinii pneumonia were reported in the United States of America in previously healthy homosexuals, to 1984 when an association between HIV and the development of AIDS was established, the world has faced a pandemic situation in its hand. ${ }^{[1]}$ The global HIV/AIDS pandemic has reached devastating proportions, especially in sub-Saharan African countries. It is estimated that over 60 million children and adults have been infected with HIV/AIDS worldwide since the beginning of the pandemic and about 20 million have died. ${ }^{[2]}$ In the near future, about 50 million people are estimated to live with the virus, of which about $95 \%$ will be in developing countries such as Nigeria. Out of every ten persons infected, seven live in sub-Saharan Africa and an estimated one-third of those living with HIV/AIDS are between 15 and 24 years of age. ${ }^{[2]}$ With the prevalence rate increasing from $1.8 \%$ in 1991 to $4.8 \%$ in $1995,5.8 \%$ in $2001,4.5 \%$ in 2005 , and presently put at $4.6 \%,{ }^{[3,4]}$ the Federal Government of Nigeria has increased its commitment in addressing the situation. The National Agency for Control of AIDS (NACA) has partnered with a lot of government ministries, agencies, and parastatal and organizations (NGOs) and together they have developed a multi-sectoral and multi-level approach to deal with the issue, and this is where the transport industry and issues comes in. 
In Nigeria, road remains the main mode of transport for the carriage of heavy goods and services as a result of the neglect of the rail and water transport system; airfreight is not commonly used in the country because of its enormous cost.

Kaduna State, which is the study state, is mainly agrarian and cash crops such as ginger and cotton in great demand by industries in other states of the federation are readily abundant. ${ }^{[5]}$ In addition, herds are constantly being moved to other parts of the country by means of Heavy Goods Vehicle (HGV) and vice versa petroleum products are conveyed to the state to meet the demands of the people. In Nigeria, for example, $95 \%$ of commercial drivers have at least one other sexual partner in addition to their respective wives, with an average of 6.4 regular girlfriends at different locations along their regular major transport routes. ${ }^{[6]}$

In a study done by Walker, it was found that large junction towns and truck shops had HIV prevalence rates based on the 2003 sero-prevalence study in Nigeria far higher than the state housing the truck shop. In her study, Lagos State, for example, had a prevalence rate of $7 \%$, whereas Badagery town had a prevalence rate of $17.4 \%$; Lokoja town in Kogi State had a prevalence of $7 \%$ whereas the state prevalence was $5.7 \%$ and some locations in the country where almost double and even doubled the national prevalence rates such as Ikom in Cross Rivers State with 11.3\% and Gadan Tanabarawa the largest truck Community in Kano State with $30 \%{ }^{\left[{ }^{[7]}\right.}$

Another study in Uganda and Kenya with high prevalence rates of HIV/AIDS showed that truck shops are always populated with commercial sex workers (CSWs). Similarly the study of the transport corridor linking Kenyan port city of Mombasa to Kampala in Uganda found that truckers accounted for $30 \%$ of the clients of CSWs along the corridor that attracts up to $5600 \mathrm{CSWs} .{ }^{[8]}$

A behavioral surveillance survey (BSS) conducted in Zambia in the year 2000 on long-distance drivers found patronage of CSWs by $30 \%$ and non-regular partners forming $22 \%$ among the respondents while on transit. ${ }^{[0]}$

Furthermore, in a study conducted in India, among 100 truckers, both married and unmarried, it was discovered that there was little and incomplete knowledge of HIV/AIDS infection, how to avoid it, and the prevention and precautionary measures to combat the deadly epidemic; more so, $30 \%$ of the respondents did not know the proper source of spread of the infection. ${ }^{[10]}$

Studies have also revealed that transport workers are twice likely to acquire HIV infection than workers in the "low-risk" occupations. ${ }^{[1]}$

Creating awareness and the necessary positive changes in behavior where the need arises, among HGV drivers plying the state routes, and improving the socioeconomic conditions of CSWs operating along the transport corridors in the state are crucial in the fight against HIV/AIDS. Therefore, determining the sexual activities and behavior of HGV drivers while on transit within Kaduna State transport corridor is crucial.

\section{MATERIALS AND METHODS}

The study area is Maraba-Jos in Igabi Local Government Area of the state, an HGV stoppage point along the Kaduna-Kano transport corridor of northern Nigeria, 10- min drive to and from the city center of Kaduna State, with an area office for the National Union of Petroleum and Natural Gas Workers (NUPENG).

Sample size was determined making use of a time-location sampling (TLS) technique whereby vehicular count was done for a period of 1 week to ascertain the number of vehicles that stopped over; a total of 1750 was counted that made a stopover. Thereafter, this number was multiplied by a factor of 2 (two individuals per truck). A total of 3500 individuals were obtained, and $10 \%$ of this amounting to 350 was used.

Therefore, for the purpose of this study, a sample size of 350 was used.

Cluster sampling technique, a probability sampling method, was utilized for questionnaire administration, which encompasses a TLS technique. Grouping (cluster) of the comfort places, drinking spots, and hotels visited by the HGV drivers while in the study area (enumeration unit) was created first that took into consideration the time at which the HGV drivers (elementary unit) making use of the stoppage point visited the different locations in the study area.

The TLS technique utilized provided the opportunity to reach the members of the target population who accessed these locations at a given point in time when in the study area.

The hours of 7.00 a.m. to 9.00 a.m. and 6.00 p.m. to 8.00 p.m. was found to be the peak time at which HGV drivers making use of the stoppage point could be easily accessed during the initial pilot survey conducted.

Therefore, the members of the target population at the enumeration points between the hours of $7.00 \mathrm{a} . \mathrm{m}$. and $9.00 \mathrm{a} . \mathrm{m}$., and $6.00 \mathrm{p} . \mathrm{m}$. and 8.00 p.m., who consented to participate in the study, were administered the questionnaire until the sample size of 350 was got.

Questionnaire administration was used in eliciting information from the drivers and the questionnaire was administered on an individual basis in a private setting that guaranteed confidentiality of information provided by each respondent.

On retrieval of the questionnaires from the field, they were collated using Epi-data software and analyzed using Epi-info (version 6.4) package. Table with frequency, percentage distribution was then used to describe the results. Prior to this, an attitude and knowledge scale was created which was used to assess the level of knowledge and the attitude of the drivers.

\section{RESULTS}

The mean age of the drivers was 38.1 years, with 112 (32.0\%) being in the age group of $30-34$ and $40-44$ years. With regard to their educational qualification, $62 \%$ had secondary education [Table 1].

Over two-thirds of the respondents $(78.0 \%)$ were able to answer correctly the questions related to knowledge about HIV/AIDS. The attitude of the drivers making use of the transport corridor was found to be good with $218(62.0 \%)$ of them answering correctly the questions on attitude [Table 2]. 
The rate of having sex varied from those who hardly had sex [154 $(44.0 \%)]$ to those who had sex at any available opportunity [84 $(24.0 \%)]$, to the drivers who had sex on a daily basis [49 $(14.0 \%)]$ while on transit, to those who had sex once a week [12 (42\%)] or once a month [6 (21\%)] [Table 3].

The educational qualifications of the drivers when compared against the rate of having sex showed that all the drivers with no formal education reported to have sex at any available opportunity when compared with those with formal education, whereas among those with formal education, drivers who have attended secondary school varied greatly when compared to others [Table 4].

The frequency of using condoms during sexual intercourse showed that $112(32.0 \%)$ of the respondents never made use of it and 91 $(26.0 \%)$ making use of it always and occasionally, whereas $56(16.0 \%)$ used it frequently [Table 5].

Drivers with no formal education were found to never make use of condoms $(100.0 \%)$ with others found to have various percentages of condom usage during sex [Table 6].

The study also looked into the attitudes of the drivers toward outreach programs with regards to the benefits of discussing issues that have to do with HIV/AIDS publicly. The study found that $91(26.0 \%)$ of the respondents were of the view that it will encourage the younger ones to be promiscuous, while $140(40.0 \%)$ agreed it will help create the necessary awareness in the society, 84 $(24.0 \%)$ were of the view that discussing the issue publicly will go against the norms of the society, and only $7(2.0 \%)$ were of the view that infected patients may become ashamed and reluctant to seek help [Table 7].

\section{DISCUSSION}

HGV driving is purely a male occupation in Nigeria and in almost all countries of the world, with majority of the respondents interviewed in this study falling in the age group of 30-34 and 40-44 years; both the age groups accounted for $32.0 \%$ each of the respondents and the mean age of the respondents was 38.1 years $\pm 1 \mathrm{SD}$. With regards to the Integrated Biological and Behavioral Surveillance Survey (IBBSS) 2007 , the mean age of the transport workers interviewed was found to be 30.5 years and the age bracket of 25-49 years accounted for $82.9 \%$ of the respondents. ${ }^{[12]}$ Whereas in the study of the high risk taking behavior of long-distance drivers in northern Nigeria, it was found that majority of the respondents were in the age group of $30-39$ years accounting for $42.3 \%$ of the respondents. ${ }^{[13]}$

Other studies found that $65.0 \%$ of the respondents were in the age group of 20-39 years, ${ }^{[14]}$ and the study along the KwaZulu-Natal region of South Africa found the mean age of the drivers to be 37 years. $^{[15]} \mathrm{It}$ is obvious, therefore, that drivers involved in haulage of goods plying the roads are within the age group of 15-49 years and are at the peak of their reproductive and productive life, an age group vulnerable to HIV infection.

Sixty-two percent of the drivers possessed secondary school education, with various percentages recorded for individuals having no formal education, Quranic education, primary school, and tertiary education, respectively. This made it easy for them to appreciate the

\begin{tabular}{|c|c|c|}
\hline & Frequency & Percent \\
\hline \multicolumn{3}{|l|}{ Age (years) } \\
\hline $20-24$ & 14 & 4 \\
\hline $25-29$ & 14 & 4 \\
\hline $30-34$ & 112 & 32 \\
\hline $35-39$ & 42 & 12 \\
\hline $40-44$ & 112 & 32 \\
\hline 45 and above & 56 & 16 \\
\hline Total & 350 & 100 \\
\hline \multicolumn{3}{|c|}{ Educational qualification of respondents } \\
\hline No formal education & 7 & 40 \\
\hline Quranic education & 35 & 10 \\
\hline Primary education & 49 & 14 \\
\hline Secondary education & 217 & 62 \\
\hline Tertiary education & 42 & 12 \\
\hline Total & 350 & 100 \\
\hline \multicolumn{3}{|c|}{ Marital status of respondents } \\
\hline Married & 238 & 68 \\
\hline Singles & 98 & 28 \\
\hline Separated & 14 & 4 \\
\hline Total & 350 & 100 \\
\hline
\end{tabular}

\begin{tabular}{lcc}
$\begin{array}{l}\text { Table 2: Knowledge and attitude of respondents } \\
\text { on HIVIAIDS }\end{array}$ & Frequency \\
\hline \multicolumn{2}{l}{ Level of knowledge } \\
Excellent & 273 & 78.0 \\
Good & 63 & 18.0 \\
Fair & 7 & 2.0 \\
Poor & 7 & 2.0 \\
Total & 350 & 100.0 \\
Attitude toward HIVIAIDS & & \\
Good & 218 & 62.0 \\
Bad & 119 & 34.0 \\
Poor & 14 & 4.0 \\
Total & 350 & 100.0 \\
\hline
\end{tabular}

\begin{tabular}{lcc}
$\begin{array}{l}\text { Table 3: Frequency of having sex of the } \\
\text { respondents }\end{array}$ & \\
\hline & Frequency & Percent \\
\hline Rate of having sex & & \\
Any available opportunity & 84 & 24.0 \\
Everyday & 49 & 14.0 \\
Once a week & 42 & 12.0 \\
Once a month & 21 & 6.0 \\
Hardly & 154 & 44.0 \\
Total & 350 & 100.0 \\
\hline
\end{tabular}

dangers involved with their occupation and to comprehend the vital messages put in place to create the needed awareness and knowledge.

The level of awareness and knowledge was found to be excellent with 


\begin{tabular}{|c|c|c|c|c|c|c|}
\hline \multirow[t]{2}{*}{ Frequency of sex } & \multicolumn{5}{|c|}{ Educational qualification of the drivers } & \multirow[t]{2}{*}{ Total } \\
\hline & No formal education & Quranic school & Primary school & Secondary school & Tertiary education & \\
\hline \multirow[t]{2}{*}{ Any available opportunity } & 7 & 7 & 21 & 49 & 0 & 84 \\
\hline & $100.0 \%$ & $20.0 \%$ & $42.9 \%$ & $22.6 \%$ & $0 \%$ & $24.0 \%$ \\
\hline \multirow[t]{2}{*}{ Everyday } & 0 & 0 & 0 & 49 & 0 & 49 \\
\hline & $0 \%$ & $0 \%$ & $0 \%$ & $22.6 \%$ & $0 \%$ & $14.0 \%$ \\
\hline \multirow[t]{2}{*}{ Once a week } & 0 & 7 & 0 & 28 & 7 & 42 \\
\hline & $0 \%$ & $20.0 \%$ & $0 \%$ & $12.9 \%$ & $16.7 \%$ & $12.0 \%$ \\
\hline \multirow[t]{2}{*}{ Once a month } & 0 & 0 & 7 & 14 & 0 & 21 \\
\hline & $0 \%$ & $0 \%$ & $14.3 \%$ & $6.5 \%$ & $0 \%$ & $6.0 \%$ \\
\hline \multirow[t]{2}{*}{ Hardly } & 0 & 21 & 21 & 77 & 35 & 154 \\
\hline & $0 \%$ & $60.0 \%$ & $42.9 \%$ & $35.5 \%$ & $83.3 \%$ & $44.0 \%$ \\
\hline Total & 7 & 35 & 49 & 217 & 42 & 350 \\
\hline
\end{tabular}

\begin{tabular}{lcc}
$\begin{array}{l}\text { Table 5: Frequency of condoms' use among the } \\
\text { respondents }\end{array}$ \\
\hline Frequency of using condoms & Frequency & Percent \\
\hline Never & 112 & 32.0 \\
Always & 91 & 26.0 \\
Occasionally & 91 & 26.0 \\
Frequently & 56 & 16.0 \\
Total & 350 & 100.0 \\
\hline
\end{tabular}

greater than half of the respondents being able to answer correctly the questions asked $(78.0 \%)$. This can be attributed to the fact that respondents in the study had secondary school education and their ability to comprehend vital messages being passed during outreach programs will be high. The level of awareness recorded in this study also matches with the findings obtained during the National Demographic and Health Survey (NDHS) study conducted nationwide, which found a 94\% awareness and knowledge of HIV/AIDS. ${ }^{[4]}$ The finding is similar to what was found in the study of long-distance drivers in northwestern Nigeria where $98.2 \%$ of the respondents had good knowledge of how HIV/AIDS could be contracted. ${ }^{[13]}$

The IBBSS study found that $69.9 \%$ of transport workers in the study had good knowledge of selected HIV prevention methods. ${ }^{[12]}$ Levels of awareness and knowledge has greatly improved when compared to earlier studies conducted on long-distance truck drivers in Nigeria, such as the study in Benin City Edo State that links the southwestern transport corridor to the eastern transport corridor showed that only $18.9 \%$ of the respondents in the study had correct knowledge of the modes of transmission of the HIV virus ${ }^{[16]}$ and the study of truckers making use of the Maidugiri transport corridor found that only $30.0 \%$ of the respondents had adequate awareness. ${ }^{[16,17]}$

Other studies conducted outside the shores of Nigeria have indicated different levels of awareness and knowledge regarding the spread of the infection among transport workers. The Abidjan-Lagos transport corridor study showed a baseline knowledge of $68.0 \%$ at commencement, which was improved upon to $82.7 \%$ before the rounding up of the study. ${ }^{[18]}$ Similarly, the Behavioral Surveillance Study in Zambia showed that long-distance drivers had good knowledge of how HIV/AIDS could be contracted, with $95.0 \%$ of the respondents in the study noting that sharing of needles plays a significant role in the spread of the infection..$^{[9]}$
This study showed that the frequency of sex and number of sexual partners while on transit varied among the drivers, from those who had sex at any available opportunity to a group of drivers who hardly had sex while on transit. With $14.0 \%$ of the respondents in this study acknowledging to having sex on a daily basis and $24.0 \%$ at any available opportunity, the ease of acquiring the infection is further increased as multiple sex partner practice will have to be in place, especially for respondents who must have sex on a daily basis.

The behavioral study done in the country found that $37.9 \%$ of the transport workers in the sampled states had more than one sexual partner, with $12.2 \%$ of them having four or more sexual partners 1 year prior to the study. ${ }^{[12]}$ Studies carried out on sexual behaviors of drivers by others found that $33.7 \%$ of the respondents in the study acknowledged having sex with other married women, $50.5 \%$ with hawkers, and $12.1 \%$ with CSWs. ${ }^{[19]}$ In the same vein, a study found that $47.0 \%$ had only one sexual partner, $81.0 \%$ had two sexual partners, and $15.0 \%$ of the respondents had three to four sexual partners. ${ }^{[20]}$

The study of drivers making use of the northwest transport corridor of the country found that $11.6 \%$ of the drivers had sex on a daily basis, with another $11.6 \%$ having sex at any available opportunity, $3.4 \%$ did not mind having sex with any partner, and $9.7 \%$ had sex with both regular and casual partners. ${ }^{[13]}$

In the Baltic State study of transport workers, $31.0 \%$ of the respondents acknowledged having four to more sexual contacts a month, with $29.4 \%$ having three to four sexual contacts, ${ }^{[21]}$ and the findings in a study in Zimbabwe showed that there existed some sexually active drivers who could not travel for 1-2 days without having sex with CSWs. ${ }^{[2]}$ With multiple sex partnership, a common phenomenon among long-distance drivers as shown in the different studies above, vulnerability to HIV infection is inevitable if there is no change in their sexual behavior.

Sexual contact remains the commonest route of acquiring the infection, World Health Organisation (WHO), Joint United Nations Programme on AIDS (UNAID) and United Nations Fund for Population Activities (UNFPA) came up with a position statement in 2004 that condom use remains the best option in protecting against the infection where it is impossible to abstain from casual sex. ${ }^{[23,24]}$ Condoms remain the best option for now, where abstinence is impossible, as a means of protection. $34.6 \%$ of the respondents 


\begin{tabular}{|c|c|c|c|c|c|c|}
\hline \multirow[t]{2}{*}{ Response } & \multicolumn{5}{|c|}{ Educational qualification of the drivers } & \multirow[t]{2}{*}{ Total } \\
\hline & No formal education & Quranic school & Primary school & Secondary school & Tertiary education & \\
\hline \multirow[t]{2}{*}{ Always } & 0 & 0 & 7 & 70 & 14 & 91 \\
\hline & $0 \%$ & $0 \%$ & $14.3 \%$ & $32.3 \%$ & $33.3 \%$ & $26.0 \%$ \\
\hline \multirow[t]{2}{*}{ Frequently } & 0 & 14 & 14 & 21 & 7 & 56 \\
\hline & $0 \%$ & $40.0 \%$ & $28.6 \%$ & $9.7 \%$ & $16.7 \%$ & $16.0 \%$ \\
\hline \multirow[t]{2}{*}{ Occasionally } & 0 & 7 & 14 & 63 & 7 & 91 \\
\hline & $0 \%$ & $20.0 \%$ & $28.6 \%$ & $29.0 \%$ & $16.7 \%$ & $26.0 \%$ \\
\hline \multirow[t]{2}{*}{ Never } & 7 & 14 & 14 & 63 & 14 & 112 \\
\hline & $100.0 \%$ & $40.0 \%$ & $28.6 \%$ & $29.0 \%$ & $33.3 \%$ & $32.0 \%$ \\
\hline Total & 7 & 35 & 49 & 217 & 42 & 350 \\
\hline
\end{tabular}

\begin{tabular}{|c|c|c|}
\hline Benefit & Frequency & Percent \\
\hline $\begin{array}{l}\text { Create more public awareness as part of } \\
\text { the solution to the problem }\end{array}$ & 140 & 40.0 \\
\hline $\begin{array}{l}\text { Encourage young people to indulge in } \\
\text { more sex }\end{array}$ & 91 & 26.0 \\
\hline Go against the tradition of the community & 84 & 24.0 \\
\hline No response & 28 & 8.0 \\
\hline $\begin{array}{l}\text { Make infected patients ashamed and } \\
\text { reluctant to seek help }\end{array}$ & 7 & 2.0 \\
\hline Total & 350 & 100.0 \\
\hline
\end{tabular}

in the study made use of condoms with their regular partners. However, the frequency of using condoms among the respondents showed that $32.0 \%$ of them never made use of it; with one-third of the respondents not making use of condoms and an additional $26.0 \%$ making use of it occasionally, the risk of infecting or getting infected increases.

Studies done on condom usage among transport workers earlier in the country also point to the fact that majority of them rarely make use of condoms. A study found that $70.0 \%$ of the respondents knew about condoms with regards to HIV prevention, with only $9.0 \%$ consistently making use of it. ${ }^{[25]}$ Likewise, another researcher discovered that over two-thirds of drivers never or rarely used condoms. ${ }^{[14]}$

Condoms are noted to be used more regularly with casual or CSWs as found in the behavioral study on transport workers, where on the average, $6.0 \%$ of the respondents made use of them with their regular partners and above $80.0 \%$ used them with casual or CSWs. ${ }^{[12]}$ With a common transport corridor linking Kaduna to Kano State and the ever mobile nature of the transport worker, HIV infection can easily be transmitted if unprotected sex without condoms occurs along the transport corridor.

The study found that the usage of condoms among the drivers was tied to their level of education. Condom usage was found to be higher among respondents with tertiary education when compared to others. The finding was noted to be similar to the findings of a study carried out on sexual practices, barriers to condom use, and its consistent use among long-distance truck drivers in Nigeria, where it was found that condom usage was higher among respondents with secondary education. ${ }^{[25]}$
Likewise, a study in India on sexual behavior among long-distance truck drivers found that drivers who have studied beyond class 10 made use of condoms always when compared to others. ${ }^{[26]}$ The frequency of using condoms against educational qualifications of the drivers in the study was noted to be statistically significant, that is, the better educated a driver is, the more likely he will make use of condoms.

In other to create the desired knowledge and awareness of the disease, various approaches have been adopted to reach out the individuals perceived to be at risk of getting infected.

The study sought to find out from the respondents their views toward discussing issues that have to do with HIV/AIDS publicly. Forty percent of the respondents considered that outreach programs were part of the solution in creating the desired awareness and knowledge among them. More worrisome was the finding that $26.0 \%$ of the respondents thought that outreach programs on HIV/AIDS may encourage the younger ones to indulge in more sex. In addition, $24.0 \%$ of the respondents considered issues regarding sex being discussed publicly going against the tradition of the community.

When negative ideas toward outreach programs exist, vital messages are likely to be lost as a result of misconceptions and the audiences going away with the wrong messages. The study done on reducing the risk of HIV infection among sex workers in South Africa noted that some truck drivers were forced to visit CSWs due to rejection from other women as a result of their occupation due to misconception arising from outreach programs that portray truckers as carriers of HIV infection. ${ }^{[27]}$

Similar misconception was found in the study carried out by the International Centre for Research on Women in Zambia where truckers are considered promiscuous people who spread the disease from place to place. ${ }^{[28]}$ Perception to outreach programs being done, such as 'Putting on the Breaks,' a preventive HIV transmission program along truck routes, showed that most truckers were disgusted with the people who supplied condoms and brochures on AIDS to them and felt that they were being stigmatized as AIDS carriers and that the prevention programs aimed at them were to blame for the resentment and hostility they received from the communities they pass through in the course of their jobs. ${ }^{[29]}$

The level of education was found to be crucial in the public discussion of HIV, as respondents with tertiary education all agreed that public discussion will help create the much needed awareness, 
and by so doing brings about changes in behaviors. The same was also noted in the NDHS study where it was reported that the proportion of men and women who supported condom education for youth increased with the level of education. ${ }^{[4]}$

\section{CONCLUSION}

HGV drivers making use of the Kaduna-Kano transport corridor are mainly middle-aged men at the peak of their productive and reproductive life, a vulnerable age to easily pick up HIV infection.

Over $25 \%$ of them were found to be singles, with an additional $4 \%$ being separated from their spouses, making it easy for casual sex partnership to exist.

With majority of the drivers possessing secondary education, the ability to comprehend the vital messages being passed across during outreach programs is high; this accounts for the high level of knowledge exhibited by the respondents about the infection. Behavioral change is essential and crucial in the fight against HIV infection among HGV drivers making use of the transport corridor, as casual sex practice and irregular use of condoms is still very much common among them notwithstanding the high level of knowledge they exhibit.

\section{Recommendations}

Based on the findings in the study, the following recommendations are put forward in other to help in the fight against the spread of HIV/AIDS infection along the transport corridor:

- To effectively improve on the level of knowledge and attitude recorded in the study, efforts must be directed toward strengthening the local HIV / AIDS association in Maraban-Jos by the Kaduna State Action Committee on HIV/AIDS by providing them with necessary materials and literatures, which will further enhance the knowledge of drivers during outreach programs.

- Erection of billboards in Maraba-Jos town and every $20 \mathrm{~km}$ along the entire transport corridor, which warn of the dangers involved in illicit sex practice without adequate protective measures, by the state action committee on HIV/AIDS.

- Erection of rest rooms for drivers making use of the stoppage point to spend the night while on transit by NUPENG and other trade unions charged with the well-being of the drivers involved in haulage of goods.

- The Federal Ministry of Transport in Nigeria in collaboration with states' ministries of transport and privately owned haulage companies should create a national databank for all drivers involved in the haulage of goods in the country, thereby making it easy to monitor the well-being of this workforce considered a high-risk group to HIV infection.

\section{REFERENCES}

1. Grmek MD. 'History of AIDS: Emergency and Origin of a Modern Pandemic'.New York Princetown University Press United State of America; 1990. p. 10-2.

2. UNAIDS. 2001 Report on the Global AIDS epidemic. Geneva 2001
3. Federal Ministry of Health, Abuja Nigeria Technical Report, National HIV/ Syphilis Sero-prevalence 2005 Sentinel Survey among Pregnant Women Attending Antenatal Clinic in Nigeria.

4. National Demographic and Health Survey (NDHS) 2008. Abuja, National Population Commission and ICF Macro, Report.

5. Kaduna Stateprofile. Available from: www.nigeriagalleria.com/Nigeria/ States_Nigeria/Kaduna_State.html. [Last cited on 2008 Nov 16].

6. Orubuloye IO, John PC. The role of high risk occupations in the spread of AIDS. Truck drivers and itinerant market women in Nigeria. Int Fam Plann Persp 1993;19:4348,71.

7. Walker JA. An Ethnographic study of sexual Networking and Population Mobility in Nigeria, HIVIAIDS in Junction Towns. Monograph series no. 1 (undated).

8. Ferguson A. Role of truck drivers in HIVIAIDS along routes in Africa, The Constella Future Study. Available from http://www.globalhealthreporting. org/article.asp?DR ID-53820 [Last cited on 2008 Dec 25].

9. Family Health International (fhi). Technical Report, 2000 Behavioural Surveillance Survey Zambia on Long Distance Truck Drivers.

10. Salam A, Janakar BP, Bhayya S. HIVIAIDS awareness among transport workers of Bijapur: Karnataka India. India J Sex Transm Dis 2001;22:10-3.

11. UNAIDS. Report on Global HIVIAIDS epidemic 2002

12. Federal Ministry of Health Abuja Nigeria. Technical Report, 2007 HIV/ STI- Integrated Biological and Behavioural Surveillance Survey (IBBSS).

13. Mamman, M. Mobility and Sex: The HIV risk taking Behaviour of Long Distance Drivers in North-Western Nigeria. Paper presented at School of Oriental and African Studies. London: University of London; 2007.

14. Oduwole M, Jeminusi OA, Aderogba OI, Okuboyejo OB. Influence of long distance truck drivers (LDTDs) HIVIAIDS Knowledge and Attitude on the use of condoms. International conference on AIDS, 2002 Jul 7-12.

15. Ramjee G, Gouws E. Prevalence of HIV among truck drivers visiting sex workers in KwaZulu-Natal, South Africa. Sex Transm Dis 2002;29:44-9.

16. Ofili AN. Knowledge, Attitude and Practice of Long Distance Divers Towards AIDS. Paper Presentation at International Conference on AIDS, 2004 Jul 11-16; 15: Abstract no D10566.

17. Gashua W, Hall TL, Hearst N. Awareness Regarding AIDS and HIV Seroprevelence in Nigerian Long Distance Truck Drivers. Paper Presentation at International Conference on AIDS, 1992 Jul 19-24;8:D423 (abstract no PoD5221).

18. World Bank. HIVIAIDS Project for Abidjan/Lagos Transport Corridor Technical Report published 2008.

19. Akintola O. Knowledge about AIDS and Risky sexual practices among commercial drivers in Ibadan, Nigeria. From studies and Report of (JAAIDS). Available from: http://www.nigeria-ai ds.org. [Last cited on 2008 Oct 14].

20. Akinyemi ZA, Augustine A, Clarke J, Anyanti J. Sex on the road. The HIV risk-taking behaviour of transport workers in Nigeria and its implication for HIVISTI transmission' A paper presented at the $4^{\text {th }}$ National Conference on HIVIAIDS in Nigeria, International Conference Centre, Abuja, May 2004.

21. World Bank Working paper no. 37. Truck Drivers and Casual Sex. An inquiry into the potential spread of HIVIAIDS in the Baltic region. Washington DC, USA: eISBN- 0821358952;2004.

22. Wilson D, Sibanda A, Nyathi B, Lamson N, Sibanda T. Ethnographic and quantitative research to design a community intervention among Long-Distance truck drivers in Zimbabwe. Focusing interventions among vulnerable groups for HIV Infection: Experiences from Eastern and Southern Africa. Nairobi: Network of AIDS Africa; 1994. p. 83-98

23. Centres for Disease Control. HUVIAIDS Surveillance Report 2001, HIV/AIDS report 2001. Available from: http://www.cdc.gov/hiv/slats/ hars 1302htm [Last cited on $2008 \mathrm{Dec} 12]$.

24. WHO/UNAIDS/UNFPA - Position Statement on Condoms and HIV prevention Jul 2004

25. Sunmola AM. Sexual practices, barriers to condom use and its consistent use among long distance truck drivers in Nigeria. AIDS Care Feb 2005 Available from Journalist Against AIDS Nigeria web site: www.nigeria-aids. org [Last cited on 2008 Nov 18].

26. Chaturvedi S, Singh Z, Banerjee A, Khera A. Sexual behaviour among long distance truck drivers. Indian J Community Med 2006;31:153-6. 
27. Karim QA, Karim SS, Soldan K, Zondi M. educing the risk of HIV infection among South Africa sex workers. Am J Public Health 1995;11:1521-5.

28. Understanding HIV-related stigma and resulting discrimination in SubSaharan Africa. 2002. International Center for Research on Women, Research Update June 2002, p. 4.

29. The Synergy Project 'Putting on the Brakes; Preventing HIV Transmission along Truck Routes'. A research based field resource supported by the synergy APDIME Toolkit. Available from: http://www.synergyaids.com [Last cited on 2009 Jan 12].
How to cite this article: Idris $\mathrm{SH}$, Sambo MN, Obi P. Comportment of heavy goods vehicle drivers in HIV spread along settlements around Kaduna: Kano road transport corridor in Nigeria. Int J Med Public Health 2013;3:26-32.

Source of Support: The study was funded purely by the authors, support was however received from NUPENG who assisted in reaching out to its members in collaborating in the study and staff of the organisation who assisted in sorting out the questionnaires, Conflict of Interest: None declared 